\title{
Synthesis, Characterization, and Evaluation of Degussa P25/Chitosan Composites for the Photocatalytic Removal of Sertraline and Acid Red 18 from Water
}

\author{
M. Rejek ${ }^{1} \cdot$ J. Grzechulska-Damszel ${ }^{1} \cdot$ B. Schmidt ${ }^{2}$ (I)
}

Accepted: 29 March 2021 / Published online: 10 April 2021

(c) The Author(s) 2021

\begin{abstract}
Degussa P25 titanium dioxide/chitosan composites (P25/CS) were prepared using three different methods and two different chitosan materials. The obtained materials were characterized by diffuse reflectance UV-Vis, Fourier-transform infrared spectroscopies, X-ray diffraction, and scanning electron microscopy. It was observed for all prepared materials that the chitosan surface is homogeneously covered by Degussa P25, the particles are evenly dispersed on the whole chitosan matrix and do not form agglomerates. The performance of P25/CS composites were tested in water treatment by the photocatalytic reaction of sertraline and Acid Red 18. The obtained results show that the application of prepared composites is effective in the reaction of decomposition of model organic impurities in water. Moreover, chitosan presence in the photocatalytic materials considerably facilitates the separation of catalyst from the reaction mixture, which is a great advantage compared to pure Degussa P25. The preparation method did not show a major effect on the photocatalytic activity. The method using glutaraldehyde as the crosslinking agent is the simplest one; thus, it is recommended for Degussa P25/chitosan nanocomposites preparation. These nanocomposites can be successfully applied in water purification by photocatalytic degradation of organic pollutants.
\end{abstract}

\section{B. Schmidt}

Beata.Schmidt@zut.edu.pl

M. Rejek

maja.rejek@gmail.com

J. Grzechulska-Damszel

Joanna.Grzechulska@zut.edu.pl

1 Department of Inorganic Chemical Technology and Environment Engineering, Faculty of Chemical Technology and Engineering, West Pomeranian University of Technology in Szczecin, Pułaskiego 10, 70-322 Szczecin, Poland

2 Department of Chemical Organic Technology and Polymeric Materials, Faculty of Chemical Technology and Engineering, West Pomeranian University of Technology in Szczecin, Pułaskiego 10, 70-322 Szczecin, Poland 


\section{Graphic Abstract}
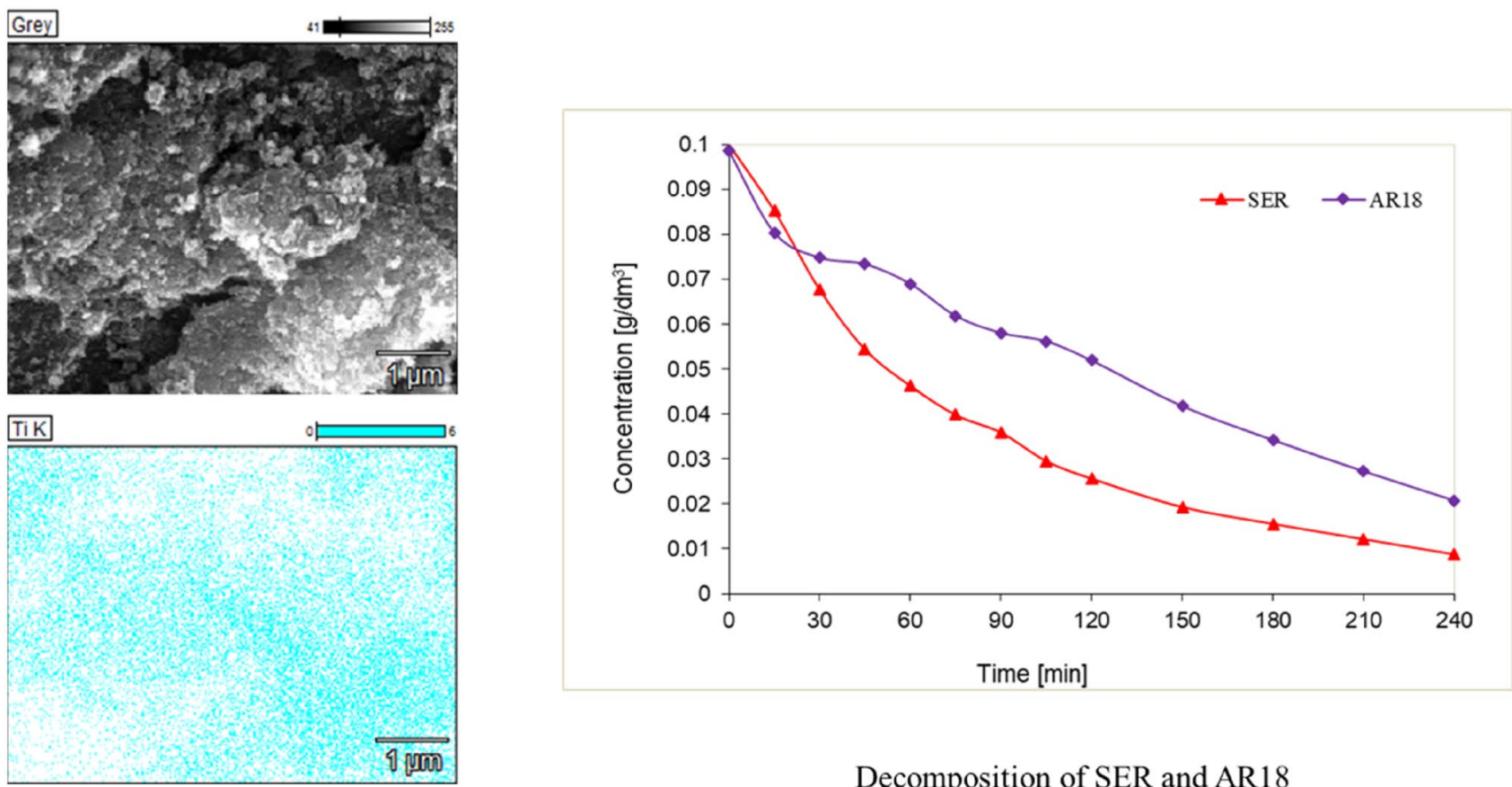

Chitosan/titania composites

Decomposition of SER and AR18

Keywords Composites $\cdot$ Photocatalysis $\cdot$ Chitosan $\cdot$ Titanium dioxide $\cdot$ Water purification

\section{Introduction}

The pharmaceutical industry is one of the most developed industry in the world, where increase in production is estimated to $6-7 \%$ per year [1]. Pharmaceuticals are biologically active, stable compounds that negatively impact many ecosystems, especially the aquatic environment [2-5].

First tests concerning the presence of medicines in water, performed by Thomas Ternes in 1998 in Germany, demonstrated anti-inflammatory drugs, analgesics, antidepressants, antiepileptics, and beta-blockers hormones, fat regulators and metabolites in rivers, streams, and sewage. Future research developed in many countries showed that residues of pharmaceuticals are present in inflow and outflow of sewage treatment plants, surface and ground water, drinking water, and seawater [1, 6-10].

Kolpin et al. [2] examined 139 streams in the United States and approximately $80 \%$ of them contain personal care products such as steroidal hormones, stimulants, antimicrobial agents, plasticizers, fire retardants, and their active and inactive metabolites. Of the 95 tested compounds the most often detected were coprostanol, cholesterol, N,N-diethyltoluamide, caffeine, triclosan, tri(2-chloroethyl)phosphate and 4-nonylphenol. Yu et al. [6] examined samples of water taken from wastewater influent, secondary effluent and West Prong Little Pigeon River in Tennessee. Their research confirmed the presence of triclosan, caffeine, ibuprofen, bisphenol A and bis(2-ethylhexyl)phthalate (DEHP) in the influent; triclosan, ibuprofen, and DEHP in the secondary effluent; triclosan and ibuprofen in the river water. Estrogens were not detected in any sample, but every sample showed estrogenic activities which can indicate the presence of unknown estrogenic compounds. Magner et al. [11] studied the presence of caffeine, metoprolol, oxazepam, and carbamazepine in two cities in Sweden: Stockholm and Södertälje. Samples collected in eight places in the Stockholm area contained a similar amount of these pharmaceuticals probably caused by the relatively closed bay to which effluents from two sewage treatment plants were introduced. In Södertälje, researchers checked what impact on the presence of medicines in water has distance from the wastewater treatment plant. For this purpose, they took samples along the coastal gradient. These studies have shown that drugs' concentration decreases when the distance from the sewage treatment plant increases, but in a varying degree for the different pharmaceuticals.

Pharmaceuticals are continuously introduced to the environment from many emission sources like: pharmacies, hospitals, health centers, farms or households. Traditional 
sewage treatment plants are not adapted to degrade this kind of pollutants. Pharmaceuticals are not totally degradable by biological processes, what results in the introduction of unknown metabolites to an aqueous environment and also their incorporation to sewage sludge often used as a fertilizer [2, 8, 12-14]. The presence of pharmaceuticals in water has a potentially negative effect on the environment by causing the development of bacteria resistant to antibiotics, decreased aquatic organism's population, and abnormal physiological processes [2]. Their presence in drinking water causes re-consumption of pharmaceuticals by humans, which can cause immunization on this kind of drugs and even increase cancer incidence [1, 2, 6, 14-17].

Conventional wastewater treatment plants are based on biological technology, which is not suitable for decomposing pharmaceutical pollutants. In recent years scientists conducted many types of research, which resulted in finding appropriate methods for remove medicines from the water like SBR reactors, membrane bioreactors, electrocoagulation or advanced oxidation processes including photocatalysis. The most promising seems to be photocatalysis because in most cases it causes complete degradation of hardly removable compounds. This process proceeds with use of UV or sunlight in the presence of semiconductor. This method's mechanism is based on generation of highly reactive hydroxyl radicals, which are one of the strongest oxidants. Thus, the photocatalytic removal of organic impurities from water is, from the chemical point of view, the oxidation process leading to mineralization of organics to water, carbon dioxide, and inorganic acids. The most frequently used photocatalysts are metal oxides and sulfides like $\mathrm{TiO}_{2}, \mathrm{ZnO}$, $\mathrm{SnO}_{2}, \mathrm{ZnS}$ or CdS. Titanium dioxide $\mathrm{P} 25$ is the most common photocatalyst, due to it is high activity, photochemical stability, resistant to $\mathrm{pH}$ changes and relatively cheap [18-25].

One of the disadvantages of $\mathrm{TiO}_{2}$ application in the suspended systems is the recovering process of the photocatalyst which is expensive and time-consuming. Immobilization of the catalytic material on the surface of natural polymers can solve this problem and also improve some properties like photoactivity or sorption.

Many of natural polymers have good adsorption properties and are used in water purification. Schmidt [26, 27] studied the adsorption of $\mathrm{Fe}^{3+}$ and $\mathrm{Cu}^{2+}$ cations from water solution on potato starch grafted acrylamide copolymers. Jiang et al. [28] prepared magnetic lignin-based materials with adsorption properties for dyes like Congo Red, Titan Yellow, Eriochrome Blue and Black R. Annadurai et al. [29] used cellulose-based wastes like banana and orange peels to prepare adsorbent for adsorption of methylene orange, methylene blue, Rhodamine B, Congo red, methyl violet and amino black 10B from the aqueous solution. Janhom et al. [30] performed studies of lac dye adsorption on the modified cotton fiber surface. Vieira et al. [31] examined adsorption of copper, mercury and chromium cations onto natural and crosslinked chitosan films.

Chitosan seems to be a good natural polymer as a base for depositing of titanium dioxide on it, due to it is nontoxicity, biocompatibility or antibacterial and antifungal properties. There is a few publication about application of $\mathrm{TiO}_{2}$-chitosan composite for removal of dyes like Rose Bengal [32], Benzopurpurin [33], Methylene Blue [33, 34], Reactive Red 2 [34], Rhodamine B [34], Alizarin Red S [35], Methyl Orange [35, 36], Reactive Red 120 [37], Reactive Yellow 17 [37] and Reactive Blue 220 [37] from aqueous solution, but this material was not examined yet for the removal of pharmaceuticals from water.

In this study, we compared three different methods for immobilization of titanium dioxide P25 onto chitosan surface (P25/CS). Two different sources of chitosan: high (HMW: 310,000-375,000) and medium (MMW: 190,000-310,000) molecular weight, were used for preparation $\mathrm{P} 25 / \mathrm{CS}$ photocatalysts. Sertraline (SER) — one of SSRI (selective serotonin reuptake inhibitor) drugs used in psychiatric treatment, was chosen to examine photoactivity of prepared materials. Seeing from other publications that this material appears to have high activity in the decomposition of many dyes it was decided to carry out the removal of Acid Red 18 (AR18)the azo dye used for staining clothes-from aqueous solution for comparison. These two impurities were not described yet in the process of the photocatalytic decomposition using titania/chitosan catalyst. The impact of the initial concentration of model compounds and the amount of photocatalyst on the reaction rate was also examined.

\section{Experimental section}

Titanium dioxide used for the production of P25/CS materials was purchased from Evonic Industries AG and both types of chitosan from Sigma Aldrich Co. Epichlorohydrin was also purchased from Sigma Aldrich Co. Acetic acid, sodium hydroxide, formalin and sodium bicarbonate were purchased from Chempur Co. Glutaraldehyde was produced by Scharlau Chemie S.A. As a model compounds sertraline in form of Asentra drug from KRKA (Slovenia) and Acid Red 18 from Boruta Zachem (Poland) were used.

The base of all three preparation methods of P25/CS was $\mathrm{TiO}_{2}$ suspension in chitosan solution (base suspension), which was received as follows. First the suitable amount of chitosan (9 g per $100 \mathrm{ml}$ of acetic acid) was dissolved in acetic acid. Titanium dioxide was added to the obtained solution and stirred continuously to obtain a good dispersion.

In the first method $(1 \mathrm{M})$ of $\mathrm{P} 25 / \mathrm{CS}$ preparation, the base suspension was left in sodium hydroxide solution for $24 \mathrm{~h}$ followed by dropwise to glutaraldehyde solution for 
crosslinking. After $48 \mathrm{~h}$ the solution was decanted from the formed sediment and left to dry at the room temperature. In the second method $(2 \mathrm{M})$ the crosslinking agent was formalin and the process took $72 \mathrm{~h}$. Sodium bicarbonate and formalin were added to the base suspension in the third method (3 M). The solution was decanted and sodium hydroxide and epichlorohydrin solution was poured to the sediment. This mixture was heated for $2 \mathrm{~h}$ and left at room temperature for $24 \mathrm{~h}$. Next, after decantation, the sediment was dried at the room temperature.

The reactions of decomposition of the model compounds were conducted in glass, periodic reactor with centrally placed mercury lamp emitting radiation from UV-Vis range (Heraeus, Germany). Suitable amount of photocatalyst was added to the solution of model compound $\left(0.1 \mathrm{~g} / \mathrm{dm}^{3}\right.$ SER or AR18) and stirred continuously in the dark for adsorption of the model compound on the photocatalyst surface. After adsorption, the UV-lamp was turn on and samples for analysis of concentration of reactants using UV-Vis spectrophotometer (Jasco International Co.) were taken after appropriate time intervals. The reaction was carried out for $240 \min (4 \mathrm{~h})$.

For characterization of the prepared materials, diffuse reflectance UV-Vis (DR-UV-Vis), Fourier-transform infrared (FTIR) spectroscopies, X-ray diffraction (XRD) and scanning electron microscopy (SEM) were used.

\section{Results and discussion}

Results of DR-UV-Vis analysis are shown in Fig. 1. Spectra of the P25 exhibit low reflectance in the range of 200-350 nm which corresponds to high absorption of UV radiation.

Pure chitosan is characterized by a wider range of light absorption, practically in the whole range of UV-Vis radiation. Spectra of the P25/CS materials has almost the same

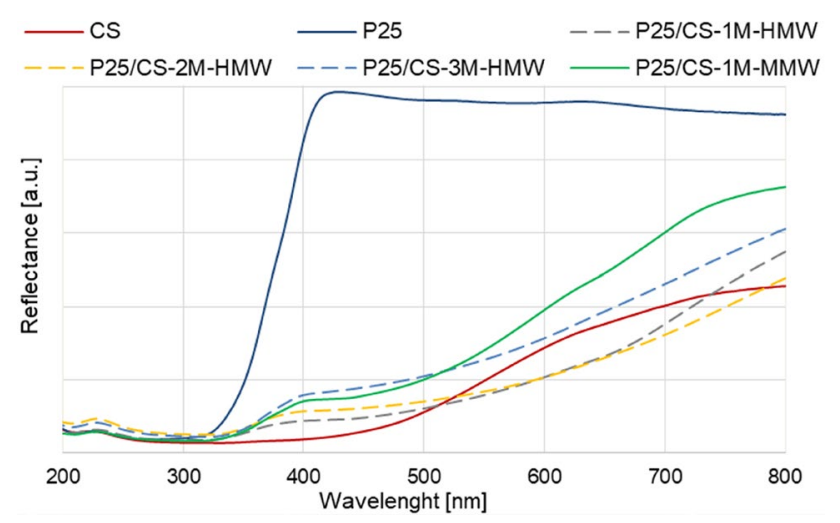

Fig. 1 Characterization of studied materials by DR-UV-Vis spectra course as pure CS with characteristic for $\mathrm{P} 25$ inflection point at $400 \mathrm{~nm}$.

FTIR results of studied materials are shown in Fig. 2. The spectra of P25/CS materials contain peaks characteristic for both substrates: P25 and chitosan. Peaks characteristic for chitosan: two peaks at 905 and $1153 \mathrm{~cm}^{-1}$ assigned to the saccharide structure; peaks at 1325,1565 and $1645 \mathrm{~cm}^{-1}$ associated with the secondary amide vibrations; at $1267 \mathrm{~cm}^{1}$ corresponding to the $\mathrm{CH}$ ring vibration; peaks at 1378 and $1420 \mathrm{~cm}^{-1}$ associated with the symmetrical deformation vibration of $\mathrm{CH}_{3}$ bend; peak at $1713 \mathrm{~cm}^{-1}$ indicates presence of the aliphatic carboxylic acid dimer; at $2975 \mathrm{~cm}^{-1}$ corresponding to the $\mathrm{CH}$ stretch vibration; the large peak in $3200-3600 \mathrm{~cm}^{-1}$ assigned to the stretching vibration of $\mathrm{OH}$ group and peak at $1570 \mathrm{~cm}^{-1}$ corresponding to $\mathrm{NH}_{3}{ }^{+}$ deformation vibration $[36,38]$. Peaks characteristic for titanium dioxide are placed at $3200-3600 \mathrm{~cm}^{-1}$ - the vibration of $\mathrm{OH}$ group, $1630 \mathrm{~cm}^{-1}$-molecular water vibration and $950 \mathrm{~cm}^{-1}$ - the vibration of $\mathrm{Ti}^{4+}$ ion coordinated by oxygen ions [39].

XRD analysis was carried out to determine the crystallinity of prepared materials. Results are shown in Fig. 3. The spectra of all P25/CS materials are characterized by peaks corresponding to both substrates-chitosan and titanium dioxide, and the major titania phase is anatase. The peak corresponding to chitosan (C) is most visible in photocatalyst prepared with medium molecular weight chitosan. Peaks belonging to $\mathrm{TiO}_{2}$ are characterized by similar intensity for all P25/CS photocatalysts. The average crystallite sizes, based on the most intense anatase peak on XRD spectra and Scherrer's equation, were calculated. Similar average crystallite sizes characterize all prepared materials: $28.8 \mathrm{~nm}$ for P25/CS-1 M-HMW, $29.8 \mathrm{~nm}$ for P25/CS-2 M-HMW, 30.4 nm for P25/CS-3 M-HMW and 28,4 nm for P25/CS-1 M-MMW (for $1 \mathrm{M}, 2 \mathrm{M}$ and $3 \mathrm{M}$ preparation methods).

To determine the distribution pattern of titanium dioxide nanoparticles on polymer, SEM analyses of pure chitosan

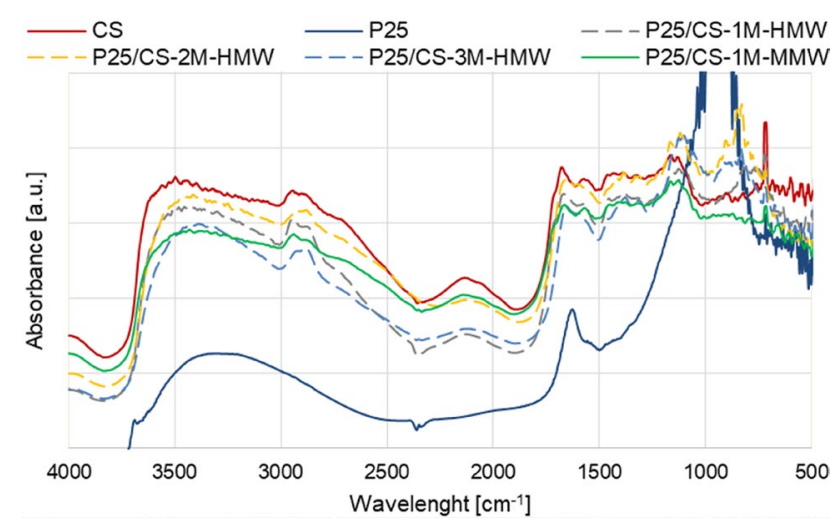

Fig. 2 Characterization of studied materials by FTIR spectra 


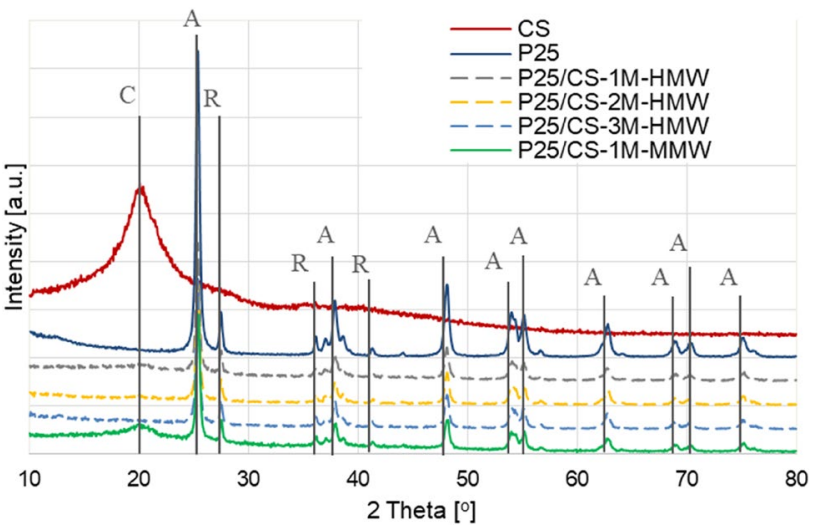

Fig. 3 Characterization of studied materials by XRD spectra (C-chitosan, A-anatase, R-rutile)

and P25/CS-1 M-MMW were done and the results are shown in Fig. 4. Chitosan is characterized by rough and irregular surface. Comparison of morphology of materials presented on both pictures confirm the presence of $\mathrm{TiO}_{2}$ on CS surface in case of $\mathrm{P} 25 / \mathrm{CS}-1 \mathrm{M}-\mathrm{MMW}$ photocatalyst. CS picture (Fig. 4a) indicates the presence of many macropores and P25/CS-1 M-MMW image (Fig. 4b) shows that all surface of CS is covered by spherical $\mathrm{TiO}_{2}$ particles. This particles are evenly dispersed on the whole chitosan matrix and do not form agglomerates, what is shown in Fig. 5.

To compare the photocatalytic activity of prepared P25/ CS materials the series of photocatalytic decomposition of SER and AR18 were carried out. To obtain the sertraline solution, the Asentra pills were powdered in an agate mortar and the appropriate amount was added to distilled water and the insoluble components were separated by filtration under reduced pressure.
A series of sorption experiments was conducted before the photocatalytic tests. It was established that the sorption process of sertraline and AR 18 onto the P25/CS materials can be neglected. As much as only about $1-1.5 \%$ of model organic impurities underwent the sorption process. The photocatalytic way of conducted processes was confirmed by total organic carbon (TOC) analysis of the reaction mixtures. The organic carbon content in the solution samples taken during the conducted processes gradually decreased, indicating the mineralization process of impurities.

The first experiments concerned the comparison of the photocatalytic activity of photocatalysts prepared by three different methods. The results are shown in Fig. 6, where it can be seen that the method of preparation does not have a major impact on the activity of the photocatalyst. Photocatalysts prepared by M1 and M3 methods showed a comparable SER removal rate after $240 \mathrm{~min}$ (about 66.3\%), a slightly lower rate was observed for photocatalyst prepared by the M2 method (around $64.5 \%$ ). Considering that the first method is relatively simple compared to the others, the material prepared using this method was applied in the next experiments.

Figure 7 presents the comparison of the photoactivity of two photocatalysts prepared by the first method with the application of two types of chitosan: high molecular weight (HMW) and medium molecular weight (MMW). The results showed that after 240 min of irradiation P25/ CS-1 M-MMW decomposed $75.7 \%$ of SER in comparison to $66.3 \%$ for P25/CS-1 M-HMW photocatalyst, so it can be declared that application of chitosan with smaller molecular weight gives the material with better activity toward SER photocatalytic decomposition. Due to the higher activity of P25/CS-1 M-MMW, further tests were performed with the application of this photocatalyst.

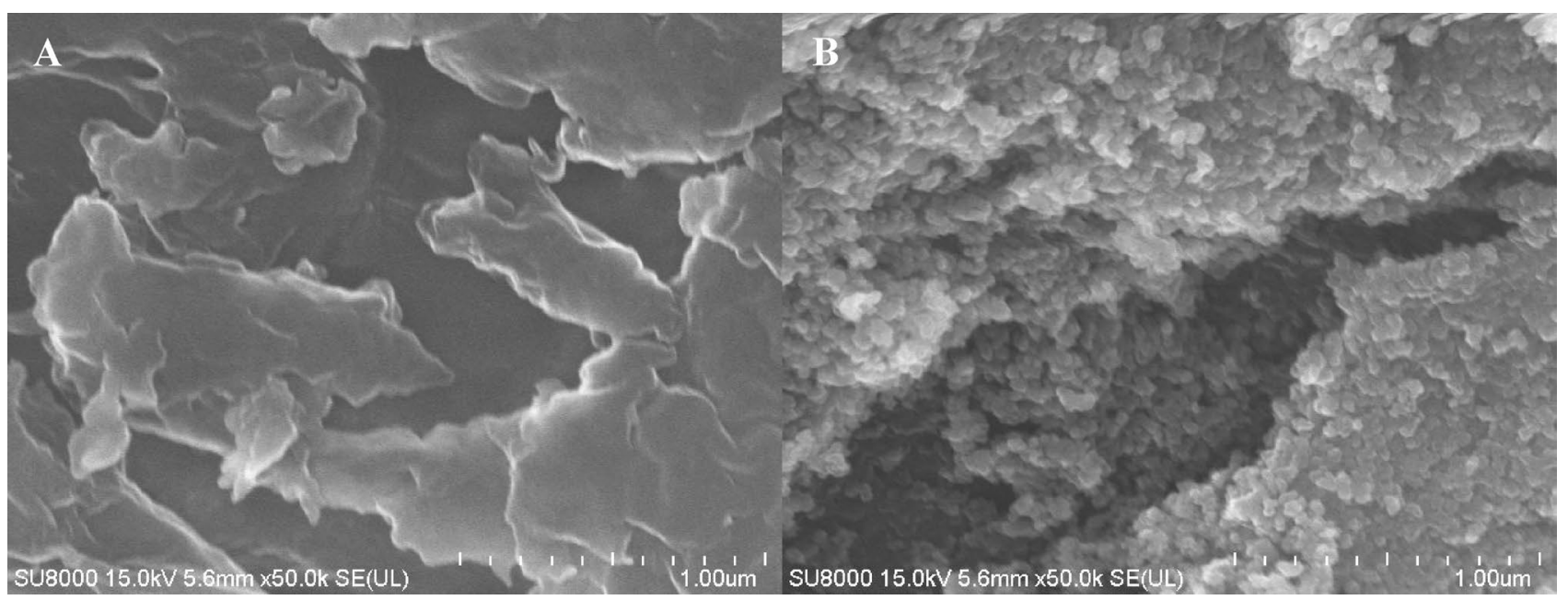

Fig. 4 SEM images of CS (a) and P25/CS-1 M-MMW (b) 


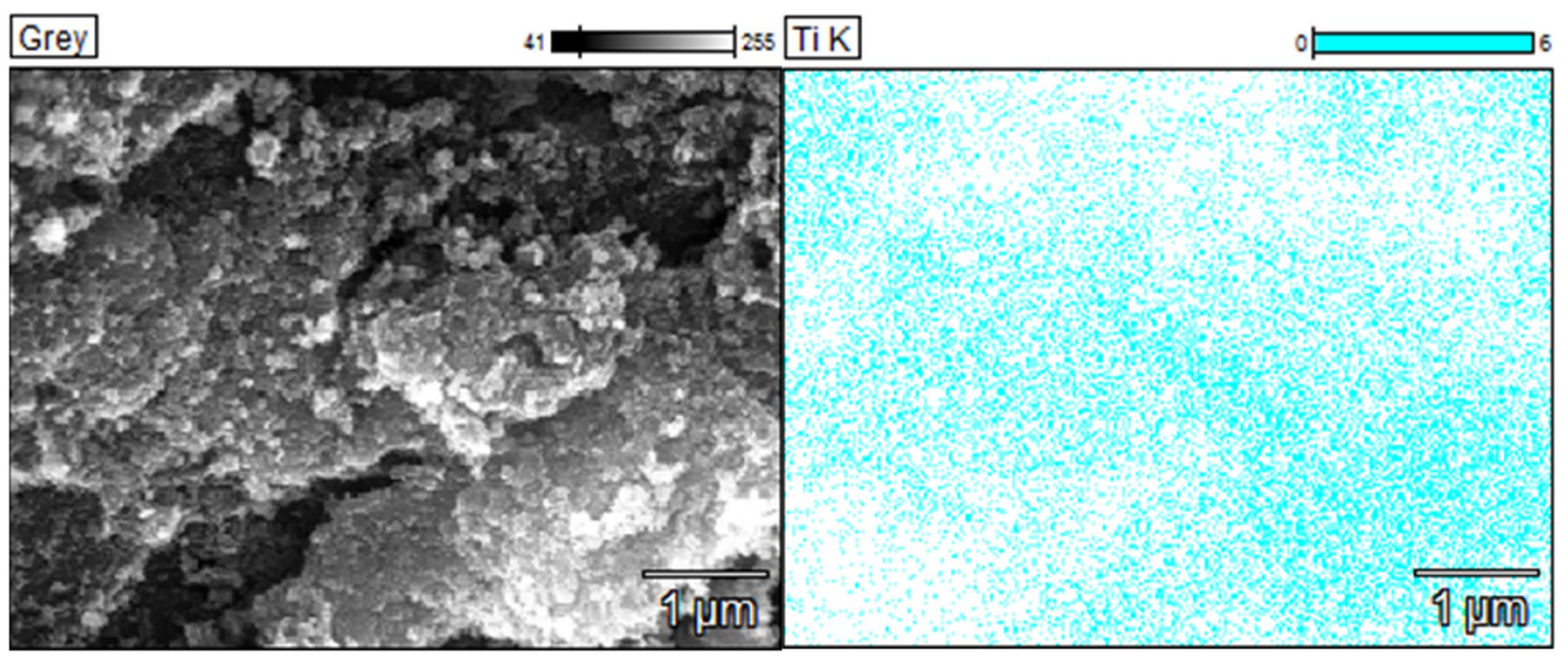

Fig. 5 Arrangement of titanium on P25/CS-1 M-MMW surface

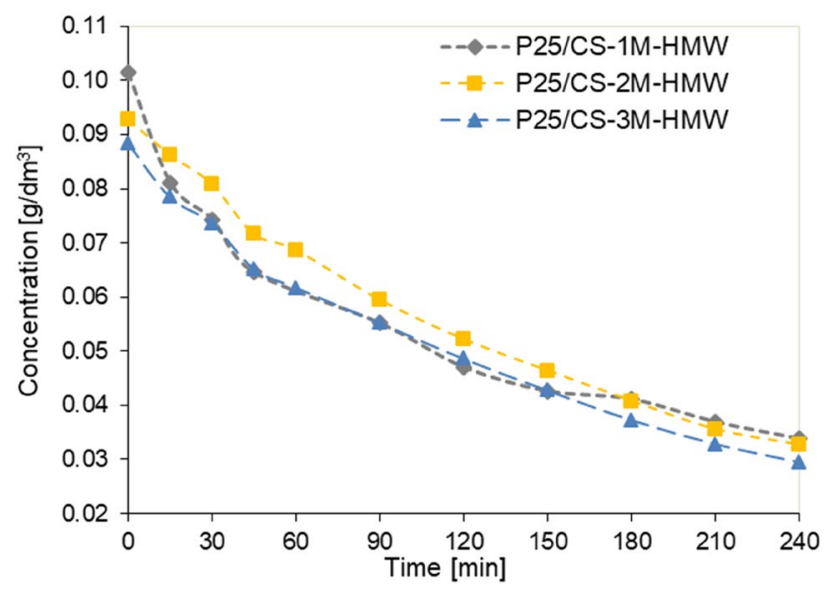

Fig. 6 Photocatalytic decomposition of SER by the P25/CS photocatalysts prepared by three different methods $\left(C_{i}=0.1 \mathrm{~g} / \mathrm{dm}^{3}\right.$, $\left.\mathrm{C}_{\mathrm{ph}}=0.4 \mathrm{~g} / \mathrm{dm}^{3}\right)$

To determine the impact of the amount of P25/ CS-1 M-MMW photocatalyst on the rate of sertraline decomposition, different doses of this material were used in the photocatalytic reactions. The results are presented in Fig. 8, where can be seen that rate of SER decomposition increases with the increasing amount of photocatalyst from $83.7 \%$ for $0.1 \mathrm{~g} / \mathrm{dm}^{3}$ to achieve about $91.2 \%$ for $0.3 \mathrm{~g} / \mathrm{dm}^{3}$ and then decreases with the increasing amount to $85.4 \%$ for $0.6 \mathrm{~g} / \mathrm{dm}^{3}$ of P25/CS-1 M-MMW photocatalyst. Decrease in rate of decomposition indicates that above $0.3 \mathrm{~g} / \mathrm{dm}^{3}$ of photocatalyst the shielding effect starts, which means that the increased opacity hinders the penetration of light through the reaction mixture.

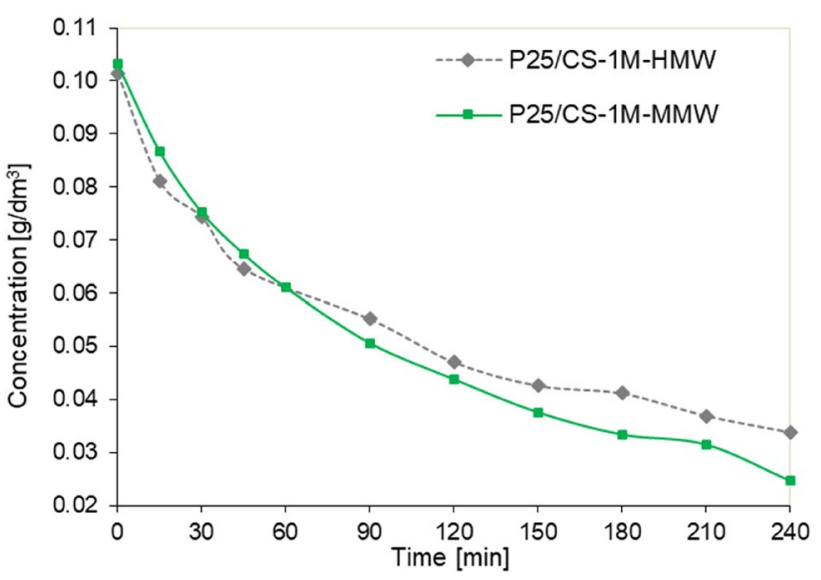

Fig. 7 Photocatalytic decomposition of SER by the P25/CS photocatalysts prepared with the application of two types of CS $\left(\mathrm{C}_{\mathrm{i}}=0.1 \mathrm{~g} /\right.$ $\mathrm{dm}^{3}, \mathrm{C}_{\mathrm{ph}}=0.4 \mathrm{~g} / \mathrm{dm}^{3}$ )

To determine the effectiveness of produced photocatalyst, it was compared to the photolytic reaction and pure P25 photocatalyst. Results presented in Fig. 9 shows, that irradiation of SER solution without the presence of the photocatalyst causes only small decomposition of this pharmaceutical reaching just $19.7 \%$ after 240 min of irradiation. Addition of $0.3 \mathrm{~g} / \mathrm{dm}^{3}$ of the photocatalyst accelerates the reaction and decomposition of SER is $91.2 \%$ for P25/CS and $91.3 \%$ for pure $\mathrm{P} 25$. This means that immobilization of $\mathrm{P} 25$ on the surface did not affected the activity of photocatalytic material.

Due to the high activity of P25/CS-1 M-MMW photocatalyst in the removal of SER from water it was decided to compare it to AR18 decomposition and results are shown in Fig. 10. 


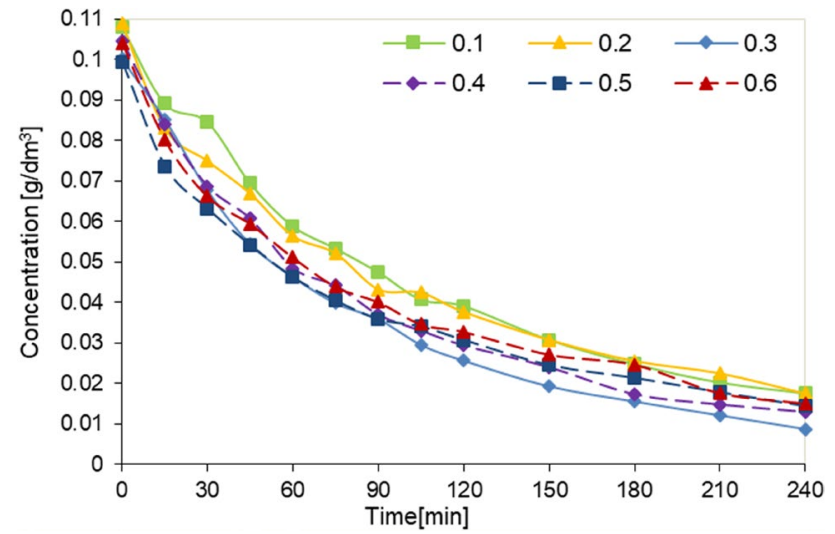

Fig. 8 Impact of the amount $\left(\mathrm{g} / \mathrm{dm}^{3}\right)$ of the P25/CS-1 M-MMW photocatalyst on the photocatalytic decomposition of SER $\left(\mathrm{C}_{\mathrm{i}}=0.1 \mathrm{~g} /\right.$ $\left.\mathrm{dm}^{3}\right)$

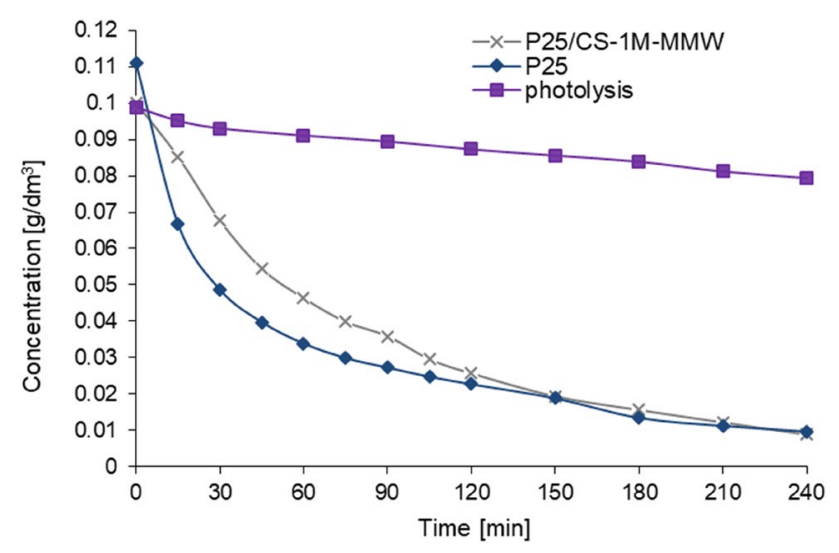

Fig. 9 Decomposition of SER by P25/CS-1 M-MMW, P25 and without photocatalyst (photolysis) $\left(\mathrm{C}_{\mathrm{i}}=0.1 \mathrm{~g} / \mathrm{dm}^{3}, \mathrm{C}_{\mathrm{ph}}=0.3 \mathrm{~g} / \mathrm{dm}^{3}\right.$ )

Figure 10 presents the results of decomposition of SER and AR18 using P25/CS-1 M-MMW. As can be seen P25/CS-1 M-MMW photocatalyst shows higher activity toward sertraline decomposition (at the same reaction conditions). After 240 min of radiation P25/CS photocatalyst decomposed $91.2 \%$ of SER and $78.9 \%$ of AR 18 .

The last test, presented in Fig. 11, shows the impact of the amount of the photocatalyst in case of AR18 decomposition. Same as in the case of SER decomposition, the rate of decomposition increases with increasing amount of $\mathrm{P} 25 / \mathrm{CS}$ to reach a certain point and then decreases with further increase of amount of the photocatalyst. In this case, the highest rate of AR18 decomposition (86.4\%) was achieved for $0.6 \mathrm{~g} / \mathrm{dm}^{3}$.

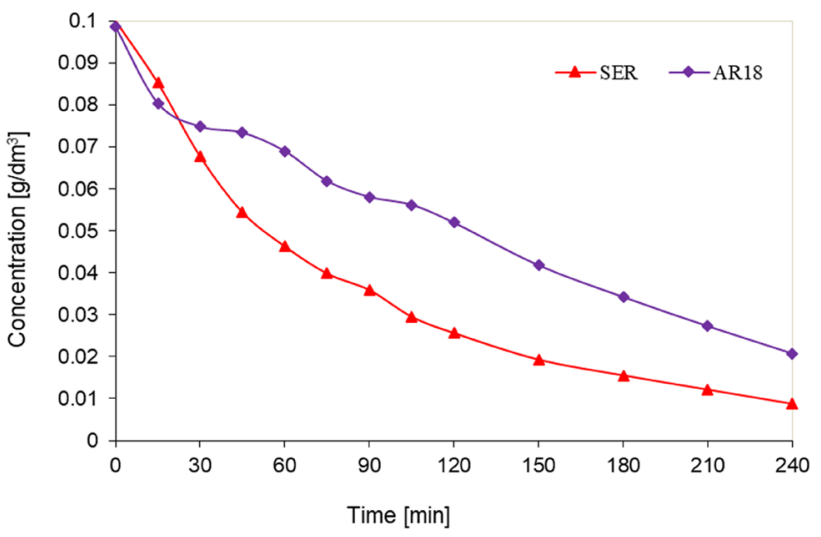

Fig. 10 Decomposition of SER and AR18 by P25/CS-1 M-MMW $\left(C_{\mathrm{i}}=0.1 \mathrm{~g} / \mathrm{dm}^{3}, \mathrm{C}_{\mathrm{ph}}=0.3 \mathrm{~g} / \mathrm{dm}^{3}\right)$

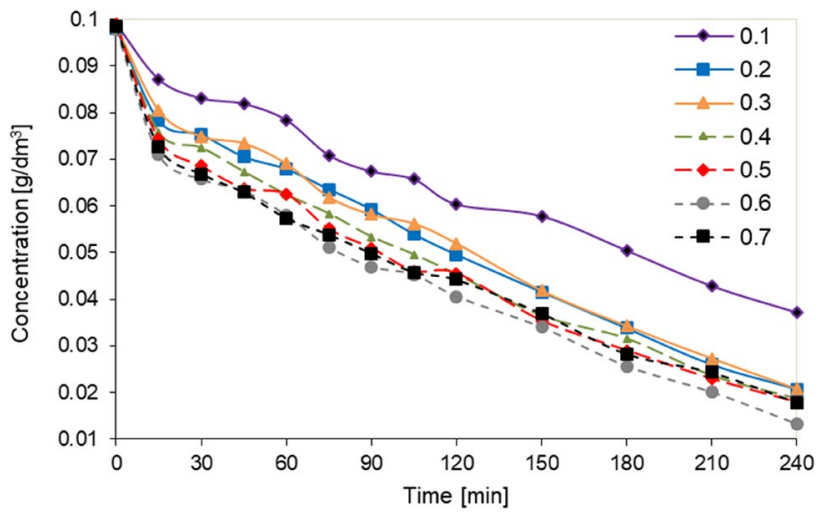

Fig. 11 Impact of the amount $\left(\mathrm{g} / \mathrm{dm}^{3}\right)$ of the P25/CS-1 M-MMW photocatalyst on the photocatalytic decomposition of AR18 $\left(C_{\mathrm{i}}=0.1 \mathrm{~g} / \mathrm{dm}^{3}\right)$

\section{Conclusions}

The results of presented studies showed that deposition of P25 titanium dioxide onto chitosan results in obtaining materials with photocatalytic activity toward decomposition of organic impurities in water. The studies of photocatalytic degradation of sertraline and Acid Red 18 by titanium dioxide P25 immobilized on chitosan showed that these photocatalysts are characterized by high, comparable to pure $\mathrm{P} 25$, photoactivity.

Three methods of preparation, using two chitosan sources, was applied to produce P25/CS composites. Titanium dioxide was evenly dispersed on the chitosan matrix, without forming of inexpedient agglomerates.

It was revealed that the preparation method does not have a major impact on the photocatalytic activity however, the use of medium molecular weight chitosan instead 
of high molecular weight chitosan results in higher rate of sertraline decomposition after $240 \mathrm{~min}$.

The amount of applied photocatalyst shows a high influence on the effectiveness of the photocatalytic reaction, due to the shielding effect occurring above a certain amount of the photocatalysts. The optimal amounts were $0.3 \mathrm{~g} / \mathrm{dm}^{3}$ and $0.6 \mathrm{~g} / \mathrm{dm}^{3}$ for sertraline and Acid Red 18 respectively. It was also shown that photocatalytic decomposition of SER runs more efficiently than the decomposition of AR18 using the same reaction conditions.

It can be concluded that materials based on $\mathrm{TiO}_{2} \mathrm{P} 25$ and chitosan can be successfully applied in the photodegradation of hard biodegradable compounds like sertraline and Acid Red 18. The photocatalytic decomposition of these compounds is much more efficient than photolysis. The presence of chitosan in the photocatalytic materials considerably facilitates the separation of catalyst from the reaction mixture, what is a great advantage comparing to pure Degussa P25.

Open Access This article is licensed under a Creative Commons Attribution 4.0 International License, which permits use, sharing, adaptation, distribution and reproduction in any medium or format, as long as you give appropriate credit to the original author(s) and the source, provide a link to the Creative Commons licence, and indicate if changes were made. The images or other third party material in this article are included in the article's Creative Commons licence, unless indicated otherwise in a credit line to the material. If material is not included in the article's Creative Commons licence and your intended use is not permitted by statutory regulation or exceeds the permitted use, you will need to obtain permission directly from the copyright holder. To view a copy of this licence, visit http://creativecommons.org/licenses/by/4.0/.

\section{References}

1. Kruszelnicka I, Ginter-Kramarczyk D, Zając A, Zembrzuska J (2012) Water Supply Sewerage 5:96

2. Kolpin DW, Furlong ET, Meyer MT, Thurman EM, Zaugg SD, Barber LB, Buxton HT (2002) Environ Sci Technol 36:1202. https://doi.org/10.1021/es011055j

3. Sangion A, Gramatica P (2016) Environ Int 95:131. https://doi. org/10.1016/j.envint.2016.08.008

4. Miller TH, Bury NR, Owen SF, MacRae JI, Barron LP (2018) Environ Pollut 239:129. https://doi.org/10.1016/j.envpol.2018.04. 012

5. Mezzelani M, Gorbi S, Regoli F (2018) Mar Environ Res 140:41. https://doi.org/10.1016/j.marenvres.2018.05.001

6. Yu C-P, Chu KH (2009) Chemosphere 75:1281. https://doi.org/ 10.1016/j.chemosphere.2009.03.043

7. Daughton CG, Ternes TA (1999) Environ Health Perspect 107:907. https://doi.org/10.1289/ehp.99107s6907

8. Ternes TA, Stumpf M, Mueller J, Haberer K, Wilken RD, Servos M (1999) Sci Total Environ 225:81. https://doi.org/10.1016/ S0048-9697(98)00337-4

9. Björlenius B, Ripszám M, Haglund P, Lindberg RH, Tysklind M, Fick J (2018) Sci Total Environ 633:1496. https://doi.org/10. 1016/j.scitotenv.2018.03.276

10. Mackulak T, Černanský S, Fehér M, Birošová L, Gál M (2019) Curr Opin Environ Sci Health 9:40. https://doi.org/10.1016/j. coesh.2019.04.002
11. Magner J, Filipovic M, Alsberg T (2010) Chemosphere 80:1255. https://doi.org/10.1016/j.chemosphere.2010.06.065

12. Heberer T (2002) Toxicol Lett 131:5. https://doi.org/10.1016/ S0378-4274(02)00041-3

13. Meyer MT, Bumgarner JE, Varns JL, Daughtridge JV, Thurman EM, Hostetler KA (2000) Sci Total Environ 248:181

14. Halling-Sorensen B, Nielsen SN, Lanzky PF, Ingerslev F, Lutzhoft HCH, Jorgensen SE (1997) Chemosphere 36:357

15. Roh H, Subramanya N, Zhao F, Yu CP, Sandt J, Chu KH (2009) Chemosphere 77:1084. https://doi.org/10.1016/j.chemosphere. 2009.08.049

16. Yu CP, Roh H, Chu KH (2007) Environ Sci Technol 41:486. https://doi.org/10.1021/es060923f

17. Kummerer K (2001) Chemosphere 45:957. https://doi.org/10 1016/S0045-6535(01)00144-8

18. Zhao L, Deng J, Sun P, Liu J, Ji Y, Nakada N, Qiao Z, Tanaka H, Yang Y (2018) Sci Total Environ 627:1253. https://doi.org/10. 1016/j.scitotenv.2018.02.006

19. Byrne C, Subramanian G, Pillai SC (2018) J Environ Chem Eng 6:3531. https://doi.org/10.1016/j.jece.2017.07.080

20. Rahimi N, Pax RA, Gray EMA (2016) Prog Solid State Chem 44:86. https://doi.org/10.1016/j.progsolidstchem.2016.07.002

21. Ohtani B (2014) Electrochem 82:414. https://doi.org/10.5796/ electrochemistry.82.414

22. Lee SY, Park SJ (2013) J Ind Eng Chem 19:1761. https://doi.org/ $10.1016 / j . j i e c .2013 .07 .012$

23. Ochiai T, Fujishima A (2012) J Photochem Photobi C Photochem Rev 13:247. https://doi.org/10.1016/j.jphotochemrev.2012.07.001

24. Henderson MA (2011) Surf Sci Rep 66:185. https://doi.org/10. 1016/j.surfrep.2011.01.001

25. Adamek E, Jakubczyk J, Baran W, Makowski A, Lipska I, Ziemiańska J, Sobczak A (2011) Proce ECOpole 5:147

26. Schmidt B (2018) Polimery 63:347. https://doi.org/10.14314/ polimery.2018.5.3

27. Schmidt B, Spychaj T (2010) Przem Chem 89:1628

28. Jiang C, Wang X, Qin D, Da W, Hou B, Hao C, Wu J (2019) J Hazard Mater 369:50. https://doi.org/10.1016/j.jhazmat.2019.02. 021

29. Annadurai G, Juang RS, Lee DJ (2002) J Hazard Mater 92:263. https://doi.org/10.1016/S0304-3894(02)00017-1

30. Janhom S, Watanesk R, Watanesk S, Griffiths P, Arquero OA, Naksata W (2006) Dyes Pigm 71:188

31. Vieira RS, Oliveira MLM, Guibal E, Rodríguez-Castellón E, Beppu MM (2011) Colloid Surface A 374:108

32. Ahmed MA, Abdelbar NM, Mohamed AA (2018) Int J Biol Macromol 107:1046

33. Zubieta CE, Messina PV, Luengo C, Dennehy M, Pieroni O, Schulz PC (2008) J Hazard Mater 152:765. https://doi.org/10. 1016/j.jhazmat.2007.07.043

34. Farzana MH, Meenakshi S (2014) Ind Eng Chem Rese 53:55. https://doi.org/10.1021/ie402347g

35. Dhanya A, Aparna K (2016) Proc Technol 24:611. https://doi.org/ 10.1016/j.protcy.2016.05.141

36. Yu F, Chen L, Ma J, Sun Y, Li Q, Li C, Yang M, Chen J (2014) RSC Adv 4:5518. https://doi.org/10.1039/C3RA46035E

37. Norranattrakul P, Siralertmukul K, Nuisin R (2013) J Metals Mater Minerals 23:9

38. Wang T, Turhan M, Gunasekaran S (2004) Polym Int 53:911. https://doi.org/10.1002/pi.1461

39. Rejek M, Kiełbasa K, Grzechulska-Damszel J (2019) Mater Eng 1:25

Publisher's Note Springer Nature remains neutral with regard to jurisdictional claims in published maps and institutional affiliations. 